\title{
Application of In-situ Synthesized TiC Reinforced Ni Based Composite Coatings by Laser Cladding on Piercing Plug
}

\author{
Yongqiang Guo \\ School of Mechanical \& Electronic Engineering \\ Tianjin Polytechnic University \\ Tianjin 300160, China \\ E-mail: gyq0818@163.com
}

\begin{abstract}
In this article, the advantages of laser cladding were briefly introduced, and a method for improving the life of piercing plug was provided by the laser cladding experiment. In situ formation of TiC particles reinforced Ni-base composite coating was prepared on the surface of piercing plug material $\mathrm{H} 13$ steel by $\mathrm{CO}_{2}$ laser. The microstructure of the clad layer was characterized by SEM, EDX and XRD. The microhardness and wear resistance of the laser clad layer was examined. The results show that laser clad layer can be achieved under technical processing parameters and that the good metallurgical bonding is formed between the coating and substrate. The coating is uniform, continuous and free of pores and cracks. The microstructure of the clad layer contains the TiC reinforced phase. The microhardness of the clad layer is $800-950 \mathrm{HV} 0.2$, about 2.5-3 times larger than that of the substrate. The clad layer is reinforced by particles and grain-refining, resulting in greatly increase in life comparing with piercing plug material H13 steel.
\end{abstract}

Keywords: Laser cladding, Piercing plug, Clad layer, Wear resistance

\section{Introduction}

In the process of rolling seamless steel pipe, the consumption of piercing plug is the biggest one of the mold (Cao, 1998, p.51-55). The piercing plug contacts directly with high-temperature steel in the production of seamless steel pipe, and bears a great friction in the process of piercing. At the same time, the piercing plug exists mechanical shock and other effects, so that it occurs much failure such as nasal cavity collapse, deformation, steel plating and cracking in the earlier. Therefore piercing plug manufacturing has become a key tool for high-quality steel pipe. The development of high-quality piercing plug is required in the production of seamless steel pipe (Zhang, 2000, p.187-190).

Laser cladding technology has developed rapidly in recent years. Some research shows that laser cladding metal matrix composite ceramic coating materials can significantly improve the wear-resistance (Qu, 2008, p.1546-1551 \& Xu, 2006, p.486-492 \& Ocelik, 2005, p.303-315). The ceramic coating particles can be getted by "plus" method, and also can be getted by "in-situ synthesis" in the process of laser cladding. In recent years, the use of "in-situ synthesis" of metal-ceramic composite coating technology has been concerned extensively at home and abroad (Li, 2006, p.8-12 \& Yang, 2006, p.519-525 \& Yang, 2002, p.26-30).

In this paper, selecting $\mathrm{NiCrBSi}(\mathrm{Ni} 60)+\mathrm{Ti}+\mathrm{C}$ as the clad material, In situ formation of $\mathrm{TiC}$ particles reinforced $\mathrm{Ni}-$ base composite coating was prepared on the surface of piercing plug by the way of laser cladding. Analysis the microstructure of the laser clad layer. Test the hardness and wear properties of the laser clad layer. It aims to improve the life of piercing plug.

\section{Experimental procedures}

H13 steel of dimensions $20 \mathrm{~mm} \times 20 \mathrm{~mm} \times 50 \mathrm{~mm}$ was used as the substrate, its chemical composition(quality scores, $\%$ ) are $0.32-0.42 \mathrm{C}, 4.75-5.5 \mathrm{Cr}, 1.1-1.75 \mathrm{Mo}, 0.8-1.2 \mathrm{~V}, 0.8-1.2 \mathrm{Si}, 0.2-0.5 \mathrm{Mn}$ and $\mathrm{Fe}$ cushion. Powder mixture of $\mathrm{NiCrBSi}(\mathrm{Ni60})+\mathrm{Ti}+\mathrm{C}$ in volume ratio of $20: 4: 1$, was used as the clad material, which was replaced on $\mathrm{H} 13$ steel with a thickness of $1 \mathrm{~mm}$.

A continuous TJ-HL-T5000 CO2 laser processing system was used for laser cladding. An overlap of 50\% between successive tracks was selected and argon gas was used as shielding gas during laser cladding process. The process parameters of laser cladding were: laser power of $1.5-2 \mathrm{~kW}$, scanning velocity of $3-10 \mathrm{~mm} / \mathrm{s}$ and laser beam diameter of $3 \mathrm{~mm}$.

The morphology of the irradiated sample was characterized by scanning electron microscopy (SEM) with QUANTA200-scanning electron microscope, which could determine the thickness of the modified layer. These studies 
were complemented with EDX. The crystalline structure was analysed by X-ray diffractometry (XRD) with D8 diffractometer. In order to get some knowledge of the mechanical properties of the treated surface, its hardness was performed by nanoindentation with HXD-1000T electron microscopy hardness, whereas the weight loss of laser clad pin-specimens was measured using a high accuracy analytic balance $\left(10^{-5} \mathrm{~g}\right)$. Surface roughness of worn surface was tested by JB-4C Precision instrument roughness.

\section{Results and discussion}

\subsection{Microstructure of laser clad coatings}

Figure 1shows a X-ray diffraction spectrums of the clad coatings. According to the indexed results of the X-ray diffraction spectrums, the main phase constituents in the coatings include: $\gamma-\mathrm{Ni}, \mathrm{Cr}_{7} \mathrm{C}_{3}$ and TiC.

Figure 2 shows the SEM micrograph of the cross-section of the coatings under different magnification. Figure 2. (a) is SEM micrographs showing the morphology under low magnification, Figure 2. (b) is SEM micrographs showing the morphology under high magnification of A zone in the Figure 2. (a). According to microstructure difference, the laser clad coatings is constitute of dendrite and lumpish particles. The lumpish particles are $1-3 \mu \mathrm{m}$.

In order to further the reaction product of the confirmation, the EDX spectrum analysis of dendrite and lumpish particles was shown in Figure 3. According to dendrite of the spectrum analysis, it is composite of (wt\%) $56.84 \mathrm{Cr}$, $1.37 \mathrm{Ti}, 20.38 \mathrm{Fe}, 12.97 \mathrm{Ni}, 7.33 \mathrm{C}, 1.10 \mathrm{Si}$, its elements for the formation of $\mathrm{Cr}$ and $\mathrm{C}$ compounds. Therefore, certain dendrite for $\mathrm{Cr}_{7} \mathrm{C}_{3}$. According to lumpish particles of the spectrum analysis, it is composite of (wt\%) 55.69Ti, $13.41 \mathrm{Cr}$, $16.58 \mathrm{C}, 2.37 \mathrm{Si}, 6.30 \mathrm{Fe}, 5.65 \mathrm{Ni}$, its elements for the formation of $\mathrm{Ti}$ and $\mathrm{C}$ compounds. Therefore, it was identified that the lumpish particles was TiC.

\subsection{Hardness of coatings and Wear resistance}

The microhardness distribution curve across the depth of the laser clad layer is plotted in Figure 4. The hardness of laser cladding in 800-950HV0.2 than the substrate increase by 2.5 to 3 times. The binding of clad layer and the substrate with the hardness is in the area around 600HV0.2.

Multi-channel laser cladding lap of the sample was cutted into $25 \mathrm{~mm} \times 7 \mathrm{~mm} \times 7 \mathrm{~mm}$, and do the wear test with GCr15. Friction process parameters: normal load $N=100 \mathrm{~N}$, sliding speed $V=400 \mathrm{r} / \mathrm{min}$, Wear time $T=3600 \mathrm{~s}$. Figure 5 show the wear weight loss of clad layer and H13 steel. Under the same wear condition, the wear weight loss of clad layer was $0.0132 \mathrm{mg}$ and the wear weight loss of H13 steel was $0.1365 \mathrm{mg}$. The wear weight loss of clad layer was 10 percent as that of $\mathrm{H} 13$ steel.

The surface roughness parameters of worn surface of laser clad layer and H13 steel in Table 1. From the Table 1, the average roughness $R a$ of worn surface, the contour maximum height $R_{\mathrm{Y}}$, the ten height $R_{\mathrm{Z}}$, the average distance $S$ of outline of an single-spacing and the average distance $S_{m}$ of profile of laser clad layer are obviously smaller than that of H13 steel. It shows that the wear track of laser clad layer is Small and shallow and the wear track of H13 steel is deep and wide.

In view of the wear test analysis, it seems that laser clad in situ $\mathrm{TiC}$ reinforced $\mathrm{Ni}$ composite coatings excellent wear resistance. It was mainly due to a lot of TiC particles was in the clad layer. When the worn of clad layer was in the process of wear, TiC particles revealed in the worn surface. On the one hand, the TiC particles which revealed in the worn surface played a supporting role. On the other hand, the TiC particles play a protection role on the substrate. Thus greatly reduce the worn of substrate. In view of the of the microstructure analysis, the microstructure of laser clad layer was very small. The clad layer not only contained the $\mathrm{Cr}, \mathrm{Fe}, \mathrm{Si}$, but also contained a lot of Ti. Thus produce grain-refining and particles strengthen and make the clad layer has high strength and toughness. It result in greatly increase in wear resistance comparing with $\mathrm{H} 13$ steel. In other words, It result in greatly increase in life comparing with piercing plug material H13 steel.

\section{Conclusions}

Crack and porous free composite coatings consisting of Ni alloy reinforced with in situ formation of TiC particles were successfully obtained by laser cladding under optimal parameters on $\mathrm{H} 13$ steel substrates from powder mixtures of Ni alloy, $\mathrm{Ti}$ and $\mathrm{C}$. The microstructure of the coating is mainly composed of $\gamma-\mathrm{Ni}, \mathrm{Cr}_{7} \mathrm{C}_{3}$ and $\mathrm{TiC}$ particles. The microhardness of the coatings is between 800 and 950HV0.2, about 2.5-3 times larger than that of the substrate. The laser clad layer is reinforced by particles and grain-refining, resulting in greatly increase in life comparing with piercing plug material H13 steel.

\section{References}

Cao, Pengjun \& Wu, Haidong. (1998). Studies about prolonging service life of piercing plug. Steel Pipe, 27(1), 51-55.

Li, Jing, Zhong, Minlin \& Liu, Wenjin. (2006). Microstructures and properties of laser clad in situ particle reinforced $\mathrm{Ni}$-Base composite coating on 55Mn steel. Heat Treatment of Metals, 31(11), 8-12. 
Ocelik, V, Matthews, D \& DeHosson J Th M. (2005). Sliding wear resistance of metal matrix composite layers prepared by high power laser. Surface and Coatings Technology, 197(2-3), 303-315.

Qu, Shiyao, Wang, Xinhong \& Zhang, Min. (2008). Microstructure and wear properties of Fe-TiC surface composite coating by laser cladding. Journal of Materials Science, 43(5), 1546-1551

Wu, Xiaolei \& Chen, Guangnan. (1998). Microstructural characteristics and wear properties of in situ Formed TiC Ceramic Reinforced metal-matrix composites coatings by laser cladding. Transactions of Metal Heat Treatment, 19(4):1-7.

$\mathrm{Xu}$, Jiang \& Liu, Wenjin. (2006). Wear characteristic of in situ synthetic $\mathrm{TiB}_{2}$ particulate-reinforced $\mathrm{Al}$ matrix composite formed by laser cladding. Wear, 260(4-5), 486-492.

Yang, Sen, Liu, Wenjin \& Zhong, Minlin. (2006). In-situ TiC reinforced composite coating produced by powder feeding laser cladding. Materials Science and Technology, 22(4), 519-525.

Yang, Sen, Zhong, Minlin \& Liu, Wenjin. (2002). Research on in-situ formation of TiC particles reinforced nickel base alloy coating produced by laser cladding. Journal of Aeronautical Materials, 22(1), 26-30.

Zhang, Xiaoping \& Hu, Jianhua. (2000). The Application of A New Surface Alloying Technique to Piercing Plug. Journal of TaiYuan Heavy Machinery Institute, 21(3), 187-190.

Table 1. Surface roughness parameters of worn surface

\begin{tabular}{|c|c|c|c|c|c|}
\hline Material & $R \mathrm{a}$ & $R_{\mathrm{Y}}$ & $R_{\mathrm{Z}}$ & $S$ & $S_{\mathrm{m}}$ \\
\hline H13 steel & 4.293 & 22.939 & 22.922 & 0.0051 & 0.0556 \\
\hline $\begin{array}{c}\text { Laser clad } \\
\text { layer }\end{array}$ & 0.655 & 4.917 & 4.877 & 0.0025 & 0.0217 \\
\hline
\end{tabular}

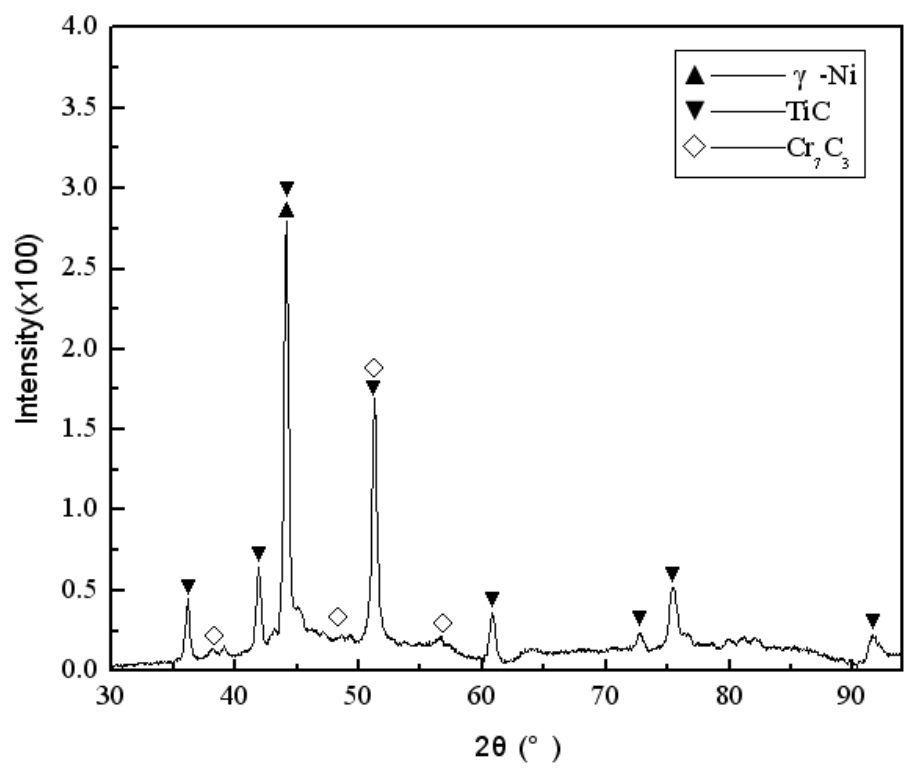

Figure 1. X-ray diffraction spectrum of laser clad layer 

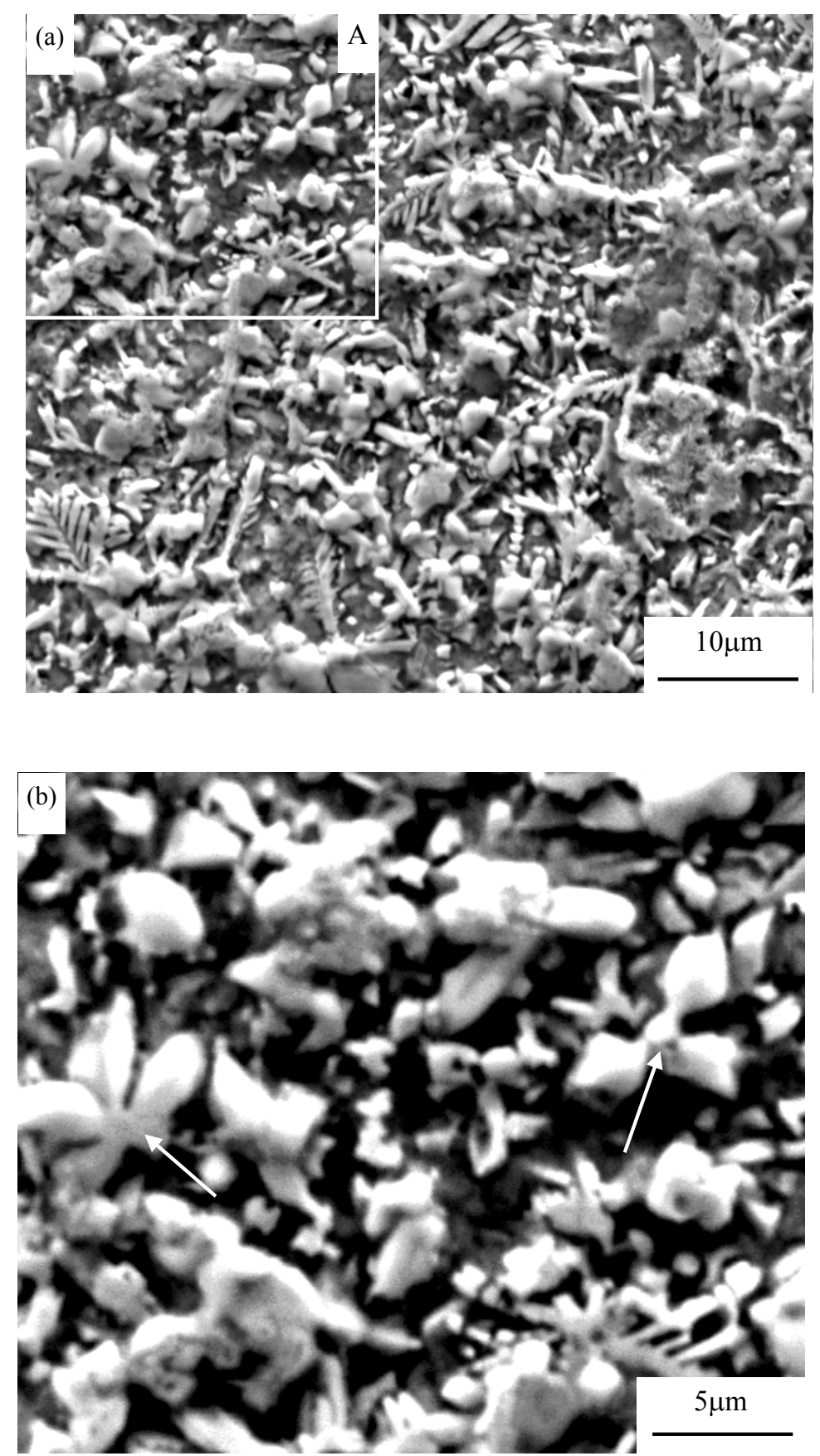

Figure 2. SEM photographs showing microstructure of clad layer (a) under low magnification; (b)A zone under high magnification 

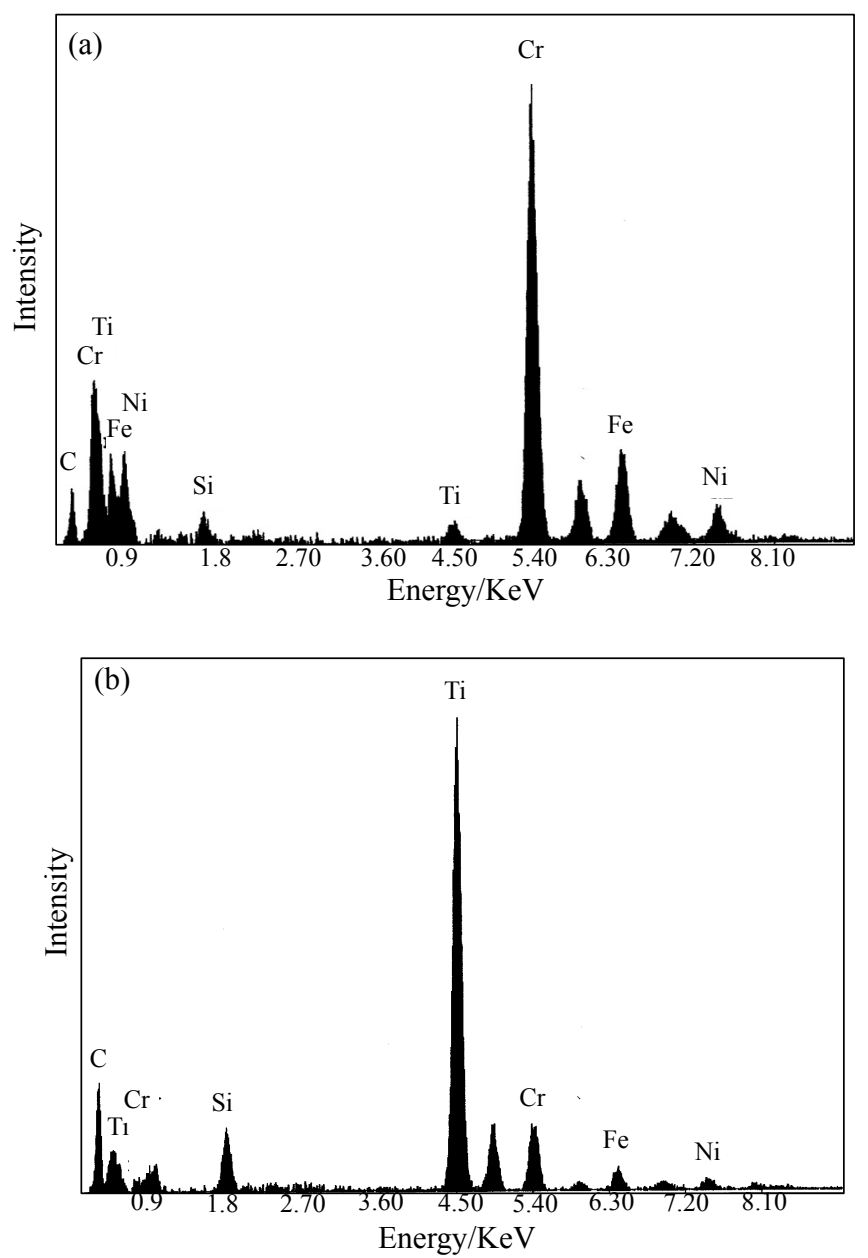

Figure 3. (a)Dendrite and (b)lumpish particles EDX spectrum

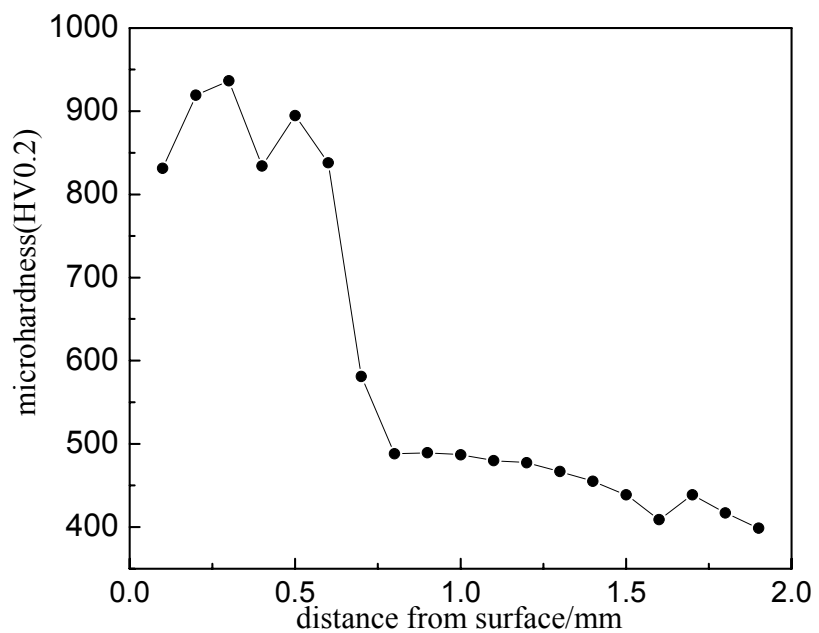

Figure 4. Microhardness distribution curve across the depth of the laser clad layer 


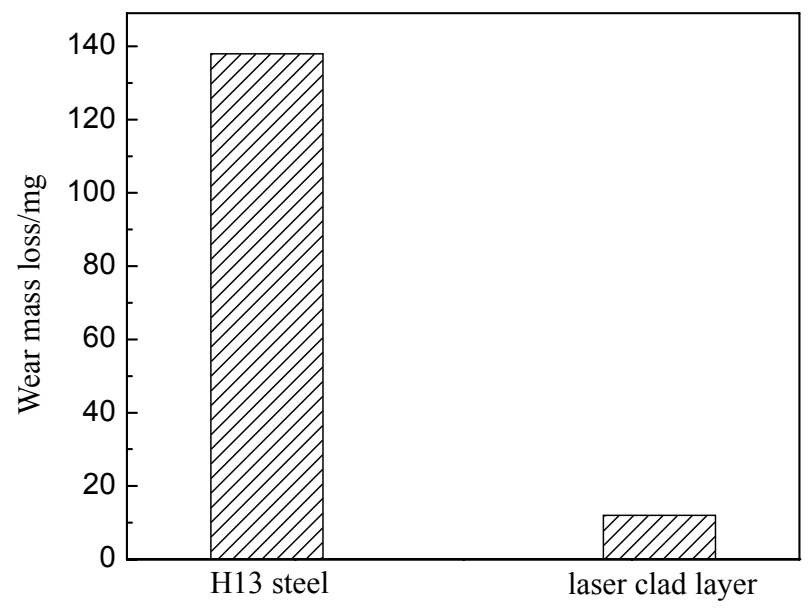

Figure 5. The wear weight loss of clad layer and H13 steel 